\title{
Self-Assessed Health Status, Walking Speed and Mortality in Older Mexican-Americans
}

\author{
Matteo Cesari ${ }^{\mathrm{a}}$ Marco Pahor ${ }^{\mathrm{a}}$ Emanuele Marzetti ${ }^{\mathrm{a}}$ Valentina Zamboni ${ }^{\mathrm{b}}$ \\ Giuseppe Collocab $^{b}$ Matteo Tosato ${ }^{b}$ Kushang V. Patel ${ }^{c}$ Jennifer J. Tovar ${ }^{d}$ \\ Kyriakos Markides ${ }^{d}$ \\ ${ }^{a}$ Department of Aging and Geriatric Research, University of Florida - Institute on Aging, Gainesville, Fla., USA; \\ ${ }^{b}$ Department of Gerontology, Geriatrics and Psychiatry, Catholic University of Sacred Heart, Rome, Italy; \\ 'Laboratory of Epidemiology, Demography, and Biometry, National Institute on Aging, National Institutes of \\ Health, Bethesda, Md., and d Department of Preventive Medicine and Community Health, University of Texas \\ Medical Branch, Galveston, Tex., USA
}

\section{Key Words}

Self-assessed health status $\cdot$ Walking speed $\cdot$ Mortality $\cdot$ Hispanic EPESE

\begin{abstract}
Background: Self-assessed health status (SAHS) and physical performance measures (in particular, walking speed) are strong predictors of health-related events. Nevertheless, the possible interaction between them in predicting major outcomes has not been clearly explored. Objective: The aim of the study is to evaluate the predictive and additive value for mortality of a SAHS measure and a walking speed test. Methods: Data are from 2,139 Mexican-Americans aged $\geq 65$ years enrolled in the Hispanic Established Populations for Epidemiologic Studies of the Elderly, and followed for 5.8 years. At the baseline visit, participants were asked to answer to the question 'How is your health in general?' presented as a four-level Likert item (i.e., poor, fair, good, excellent). They were also asked to 'walk down and back as fast as it felt safe and comfortable' along an 8-ft track. Cox proportional hazard models, receiver operating characteristic (ROC) curve, and specificity/sensitivity analyses were performed to evaluate the predictive value of SAHS and walking speed for mortality. Results: The mean age of the sample was 72.1 years.
\end{abstract}

Participants reporting 'poor' SAHS were more likely to die compared to those with 'excellent' SAHS, even after adjustment for potential confounders (HR 1.52, 95\% Cl 1.10-2.10). Similar results were obtained for participants with slow walking speed $(<0.29 \mathrm{~m} / \mathrm{s} ; \mathrm{HR} 1.68,95 \% \mathrm{Cl} 1.27-2.24$; reference group: walking speed $\geq 0.81 \mathrm{~m} / \mathrm{s}$ ). A statistically significant, but weak, correlation between SAHS and walking speed was observed (Pearson's $r=0.069, p=0.001$ ). No significant differences in areas under curves from ROC analyses were reported for the prediction of mortality when the SAHS and walking speed were tested (alone or in combination). Both tests presented high specificity ( $\geq 80 \%$ ) for the prediction of mortality. Conclusion: SAHS and walking speed are not only significant and independent predictors of mortality in older Mexican-Americans, but also present a similar predictive value. The additive prognostic value of the two measures is limited.

Copyright $\odot 2008$ S. Karger AG, Basel

\section{Introduction}

The use of physical function measures has been repeatedly encouraged in clinical as well as in research settings for a better evaluation of older persons' health status

\section{KARGER}

(C) 2008 S. Karger AG, Basel

Fax +4161306 1234

E-Mail karger@karger.ch

www.karger.com
Accessible online at:

www.karger.com/ger
Matteo Cesari, $\mathrm{MD}, \mathrm{PhD}$

Department of Aging and Geriatric Research

University of Florida - Institute on Aging

PO Box 112610, Gainesville, FL 32611 (USA)

Tel. +1 352 274 5917, Fax +1 352273 5920, E-Mail macesari@gmail.com 
[1]. Nevertheless, the clinical visit still commonly relies on information provided to the physician by the patient and/or proxies. The reluctance in adopting physical function measures for the standard assessment might be due to the higher burden of clinical conditions and the longer medical history characterizing older persons and implying more time for the visit.

Physical performance measures (and especially walking speed tests $[2,3]$ ) are important predictors of major outcomes (including disability $[2,4,5]$ and mortality $[3$, 5]). Moreover, they have also been associated with agerelated subclinical conditions (such as inflammation [6] and sarcopenia $[7,8])$. It is noteworthy that physical performance measures are predictive of health-related events even among healthy and well-functioning older persons [9], so to potentially serve as useful screening instruments.

In a similar way, self-assessed health status (SAHS) has been shown to significantly predict negative outcomes (including disability [10] and mortality [11-14]). Several mechanisms potentially explaining its predictive value have been proposed in literature. It has been suggested that SAHS might better capture the burden of clinical and subclinical conditions compared to the traditionally adopted measures of disease, possibly because inclusive of a wider spectrum of information (e.g., personal sensations). It is also possible that positive self-ratings may mirror a general optimistic disposition [15], promoting the activation of a virtuous cycle with beneficial effects on neurological, immunological and endocrinological mechanisms [16].

In a recent study conducted on 257 Finnish men, Lyyra et al. [16] showed that the relationship between SAHS and mortality was independent of several potential confounders, including physical function (i.e., isometric muscle strength). However, the possible interaction between physical performance measures and self-perceived health status in the prediction of events has never been specifically explored. Given the important role that SAHS and physical performance measures may have in the screening process of older persons, the study of this issue is of relevant clinical interest. The risk estimate of negative events may be improved by simultaneously considering measures of physical performance and SAHS. In the present study, we hypothesized that (1) physical performance and SAHS are both predictive of mortality in older persons, and (2) a possible additive effect of these two screening instruments improves the prediction of events.

This paper presents results from analyses performed in a large sample of older Mexican-Americans and aims at evaluating the predictive value for mortality of SAHS and walking speed. Besides comparing the predictive value of the two tests, analyses were also conducted to estimate whether the mortality risk was higher according to the number of tests scoring poorly.

\section{Methods}

Data are from the Hispanic Established Populations for Epidemiologic Studies of the Elderly (H-EPESE). The baseline visit of this prospective cohort study was performed from September 1993 to June 1994 on a representative sample of communitydwelling Mexican-American elderly, aged $\geq 65$ years, residing in the five South-Western states of Arizona, California, Colorado, New Mexico, and Texas. The primary aim of the H-EPESE study was to estimate the prevalence of key physical and health conditions in older Mexican-Americans, and to compare these findings to those from other populations. The H-EPESE study methods and participants' recruitment process were previously published [17-19].

Informed consent was obtained from study participants. The $\mathrm{H}$-EPESE study was conducted in compliance with the requirements of the University of Texas Medical Branch Institutional Review Board/Human Subjects' Research Committee. The total number of subjects surveyed at baseline was 3,050. The present study used baseline data and data obtained at the 2-, 5-, and 7-year follow-up visits.

The present analyses were performed on a sample of 2,139 participants, after exclusion of participants with missing values for the variables of interest (SAHS measure $n=318$, walking speed test $\mathrm{n}=640$ [among these latter, 296 refused or were unable to walk]), and/or lost during the follow-up $(n=212)$. Participants excluded from the present analyses $(n=911)$ were significantly $(\mathrm{p}<0.05)$ older, more likely to be depressed, cognitively impaired, and physically disabled compared to those included in the present study sample. They also tended to report higher prevalence of clinical conditions. Included vs. excluded participants did not significantly differ according to gender.

\section{Mortality}

Mortality was evaluated at the time of follow-up visits and validated by the National Death Index. The follow-up time considered for the present analyses was calculated as the time from the date of baseline visit to the date of death (for participants who died during the follow-up), and censored to the last contact date for participants who did not die during the study follow-up.

\section{Self-Assessed Health Status}

At the baseline visit, a single-item measure of SAHS was administered to all the participants [20]. Subjects were asked to answer to the question 'How is your health in general?' rating their status as 'excellent', 'good', 'fair', or 'poor'. The relative score ranging from 1 (best) to 4 (worst) was used for the present analyses. SAHS measures have been shown to be predictive of major health-related events, including disability [10] and mortality [11-14]. 


\section{Walking Speed Test}

At the baseline visit, participants were asked to 'walk down and back as fast as it felt safe and comfortable' for them along an 8 -ft track. The performance was timed and results (in s) recorded. For a better comparison with the 4-level variable of SAHS, walking speed (in $\mathrm{m} / \mathrm{s}$ ) was categorized into four groups by using the same population percentiles observed for the different SAHS levels (i.e., SAHS cut-points: 'poor-fair' 13th percentile, 'fair-good' 58th percentile, 'good-excellent' 87th percentile). Based on these percentiles, four groups (numerically similar to the SAHS groups) were then identified for the walking speed $(<0.29 ; 0.29-0.53$; $0.54-0.80 ; \geq 0.81 \mathrm{~m} / \mathrm{s}$ ). Consistent findings with those reported in the present paper were obtained when analyses were performed categorizing the walking speed variable into quartiles (results available upon request). Spearman's correlations between the adopted physical performance measure and the more commonly used 8 - $\mathrm{ft}$ walking test showed a regression coefficient of 0.699 $(\mathrm{p}<0.001)$ in this study sample.

\section{Covariates}

Baseline sociodemographic characteristics (age, gender, smoking status, house income) were self-reported by the study participants or provided by proxies. Smoking status was considered as 'current' if participants reported to have smoked at least 100 cigarettes in their lifetime and currently smoke. The presence of diseases was assessed by asking participants whether a doctor had ever told them that they had a certain condition. The definition of hypertension also considered baseline blood pressure levels $\geq 140 / 90 \mathrm{~mm} \mathrm{Hg}$. Body mass index (BMI) was calculated by dividing weight (in $\mathrm{kg}$ ) and squared height (in $\mathrm{m}$ ). Obesity was considered as present when participants had a BMI $\geq 30 \mathrm{~kg} / \mathrm{m}^{2}$. Depressive symptomatology was measured with the CES-D scale (continuous score, range $0-60$, where higher scores indicate the presence of more depressive symptomatology) [21]. Cognitive function was evaluated using the MMSE instrument (continuous score, range $0-30$, where higher scores indicate higher cognitive function) [22]. Physical disability was assessed using the number of impaired activities of daily living (ADL, range 0-6) [23] and instrumental activities of daily living (IADL, range 0-8) [24].

\section{Statistical Analysis}

Means (SD) and proportions (as percentage) were calculated to describe the main characteristics of the study sample. $\chi^{2}$ and $t$ test analyses according to vital status at the end of the follow-up were performed. Unadjusted and adjusted proportional hazard models were performed to estimate the hazard ratios (HR, and 95\% confidence intervals (95\% CI)) for mortality of walking speed and SAHS variables. All the sociodemographic and clinical variables showing a statistically significant difference at the univariate analyses according to vital status at the end of follow-up were included as covariates in the adjusted models. Kaplan-Meier survival curves for mortality were also performed according to physical performance and SAHS groups. Receiver operating characteristic (ROC) curve analyses were computed to estimate the predictive value of the independent variables of interest for mortality (alone and in combination) through the evaluation of the areas under the curves (AUCs). Specificity and sensitivity of walking speed and SAHS cut-points for mortality were also calculated. A $p$ value $<0.05$ was chosen for statistical significance for all the present analyses.
Table 1. Main characteristics ${ }^{1}$ of the study sample $(n=2,139)$ according to vital status at the 7-year follow-up visit

\begin{tabular}{|c|c|c|c|}
\hline & $\begin{array}{l}\text { Survived } \\
(\mathrm{n}=1,423)\end{array}$ & $\begin{array}{l}\text { Deceased } \\
(n=716)\end{array}$ & $\mathrm{p}$ \\
\hline Age, years & $70.9 \pm 5.0$ & $74.5 \pm 6.7$ & $<0.001$ \\
\hline Gender, women & 60.9 & 49.7 & $<0.001$ \\
\hline Current smoking & 12.3 & 15.5 & 0.04 \\
\hline House income USD $<10,000$ & 56.7 & 57.6 & 0.71 \\
\hline Body mass index $\geq 30 \mathrm{~kg} / \mathrm{m}^{2}$ & 32.2 & 24.9 & $<0.001$ \\
\hline CES-D score & $8.4 \pm 8.7$ & $9.5 \pm 9.0$ & 0.007 \\
\hline \multicolumn{4}{|l|}{ Mini Mental State } \\
\hline Examination score & $25.9 \pm 3.6$ & $25.0 \pm 3.8$ & $<0.001$ \\
\hline Asthma & 2.2 & 2.5 & 0.63 \\
\hline Cancer & 3.4 & 7.7 & $<0.001$ \\
\hline Diabetes & 21.0 & 33.6 & $<0.001$ \\
\hline Hip fracture & 1.8 & 2.8 & 0.15 \\
\hline Heart attack & 8.0 & 11.0 & 0.02 \\
\hline Hypertension & 60.5 & 66.4 & 0.007 \\
\hline Osteoarthritis & 39.1 & 35.7 & 0.13 \\
\hline Renal disease & 0.5 & 1.1 & 0.10 \\
\hline Stroke & 3.2 & 5.3 & 0.02 \\
\hline Thyroid disease & 0.8 & 0.4 & 0.27 \\
\hline Number of impaired ADL & $0.05 \pm 0.43$ & $0.11 \pm 0.62$ & 0.005 \\
\hline Number of impaired IADL & $0.73 \pm 1.27$ & $1.09 \pm 1.50$ & $<0.001$ \\
\hline SAHS & & & $<0.001$ \\
\hline Excellent & 14.3 & 9.9 & \\
\hline Good & 30.1 & 26.5 & \\
\hline Fair & 44.6 & 46.4 & \\
\hline Poor & 11.0 & 17.2 & \\
\hline Walking speed & & & $<0.001$ \\
\hline$\geq 0.81 \mathrm{~m} / \mathrm{s}$ & 20.0 & 12.0 & \\
\hline $0.53-0.80 \mathrm{~m} / \mathrm{s}$ & 22.6 & 19.3 & \\
\hline $0.29-0.53 \mathrm{~m} / \mathrm{s}$ & 46.4 & 50.3 & \\
\hline$<0.29 \mathrm{~m} / \mathrm{s}$ & 11.1 & 18.4 & \\
\hline
\end{tabular}

CES-D = Center for Epidemiological Studies - Depression Scale; $\mathrm{ADL}=$ activities of daily living; $\mathrm{IADL}=$ instrumental activities of daily living.

${ }^{1}$ Expressed as means \pm SDs, or percentages.

\section{Results}

The main characteristics of the study sample ( $\mathrm{n}=$ 2,139 ) are reported in table 1 according to vital status at the end of the follow-up (mean follow-up length 5.77 years). During this time, 716 (33.5\%) events occurred in the study sample. Compared to survivors, participants who died during the follow-up were older, more likely to be men and current smokers, and had a higher prevalence of cancer, diabetes, heart attack, hypertension, and stroke. 

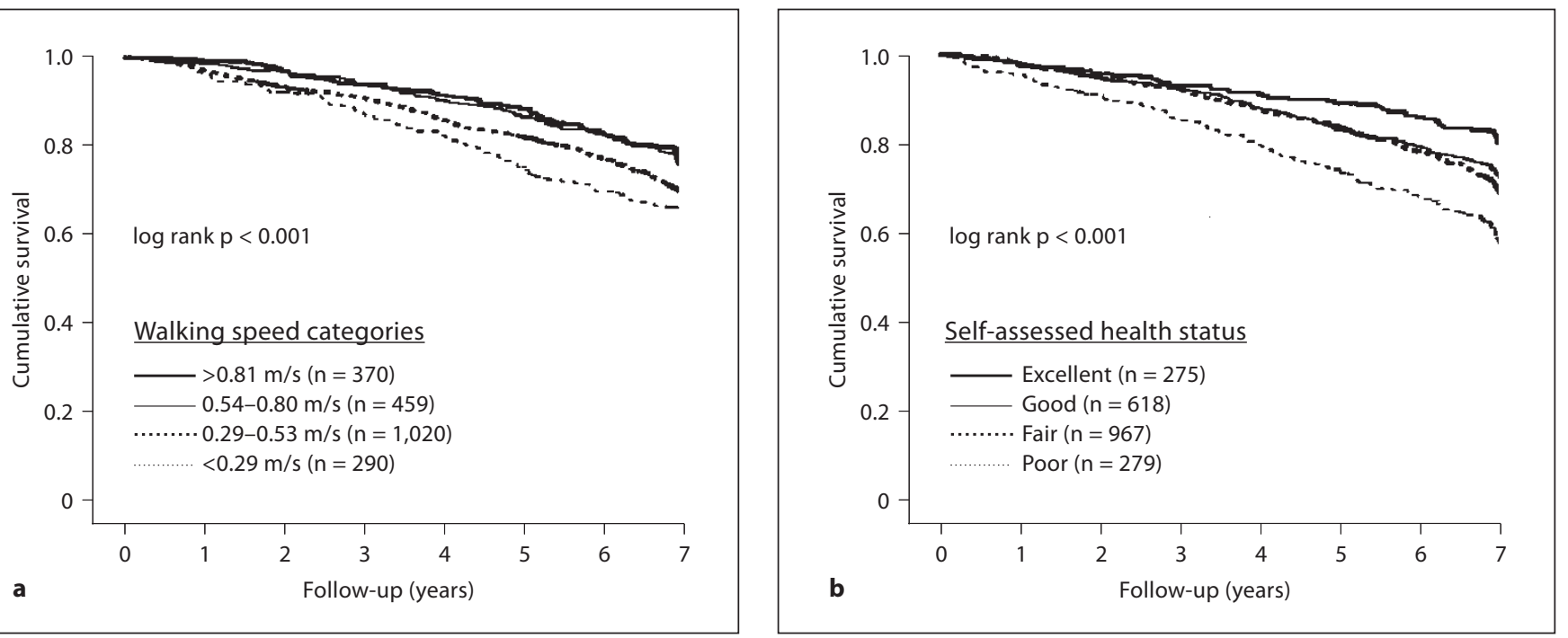

Fig. 1. Kaplan-Meier survival curves for mortality according to walking speed categories (a) and SAHS (b).

Table 2. Results (HR and 95\% CI) from proportional hazard models estimating the predictive value of SAHS and walking speed for mortality

$\begin{array}{llll}\text { Model 1 } & \text { Model 2 } & \text { Model 3 } & \text { Model 4 } \\ \text { HR }(95 \% \text { CI }) & \text { HR }(95 \% \text { CI }) & \text { HR }(95 \% \text { CI }) & \text { HR (95\% CI) }\end{array}$

\begin{tabular}{lllll}
\hline SAHS & & & \\
$\quad$ Excellent $(\mathrm{n} / \mathrm{N}=71 / 275)$ & 1 & 1 & 1 & 1 \\
Good $(\mathrm{n} / \mathrm{N}=190 / 618)$ & $1.18(0.90-1.55)$ & $1.10(0.83-1.46)$ & $1.11(0.83-1.47)$ & $1.09(0.82-1.45)$ \\
Fair $(\mathrm{n} / \mathrm{N}=332 / 967)$ & $1.32(1.02-1.71)^{*}$ & $1.13(0.86-1.48)$ & $1.13(0.86-1.49)$ & $1.11(0.85-1.46)$ \\
Poor $(\mathrm{n} / \mathrm{N}=123 / 279)$ & $2.10(1.57-2.82)^{*}$ & $1.56(1.13-2.15)^{*}$ & $1.55(1.12-2.14)^{*}$ & $1.53(1.10-2.11)^{*}$ \\
Walking speed & & & & \\
$\geq 0.81 \mathrm{~m} / \mathrm{s}(\mathrm{n} / \mathrm{N}=86 / 370)$ & 1 & 1 & 1 & 1 \\
$0.54-0.80 \mathrm{~m} / \mathrm{s}(\mathrm{n} / \mathrm{N}=138 / 459)$ & $1.26(0.96-1.66)$ & $1.21(0.92-1.59)$ & $1.21(0.92-1.60)$ & $1.23(0.94-1.62)$ \\
$0.29-0.53 \mathrm{~m} / \mathrm{s}(\mathrm{n} / \mathrm{N}=360 / 1,020)$ & $1.53(1.21-1.94)^{*}$ & $1.40(1.10-1.78)^{*}$ & $1.40(1.10-1.79)^{*}$ & $1.42(1.12-1.81)^{*}$ \\
$<0.29 \mathrm{~m} / \mathrm{s}(\mathrm{n} / \mathrm{N}=132 / 290)$ & $1.89(1.44-2.50)^{*}$ & $1.71(1.29-2.26)^{*}$ & $1.71(1.29-2.26)^{*}$ & $1.70(1.28-2.26)^{*}$ \\
\hline
\end{tabular}

${ }^{*} \mathrm{p}<0.05 . \mathrm{n} / \mathrm{N}=$ Number of events/number of participants.

Model 1: adjusted for age and gender. Model 2: adjusted for Model 1 covariates + current smoking, BMI $\geq 30 \mathrm{~kg} / \mathrm{m}^{2}$, Mini Mental State Examination score, CES-D score, cancer, diabetes, heart attack, hypertension, stroke. Model 3: adjusted for Model 2 covariates + number of impaired ADLs, number of impaired IADLs. Model 4: proportional hazard model (Model 3 adjustment) in which the independent variables of interest (SAHS and walking speed) are simultaneously included as predictors of mortality.
They also had a lower prevalence of obesity, lower MMSE scores, and higher CES-D scale scores. Participants who died also had a higher number of impaired ADLs and IADLs. Regarding the variables of interest for the present study, significant differences between participants who died versus survivors were reported for both the SAHS and the walking speed categories.

Self-Assessed Health Status, Walking Speed and Mortality
In figure 1, Kaplan-Meier survival curves for mortality according to the walking speed categories (fig. 1a) and the SAHS (fig. 1b) are presented. Pairwise comparisons performed across the SAHS groups showed that participants reporting a 'good' health status were not significantly different from those reporting an 'excellent' or 'fair' health status. All the other comparisons across 


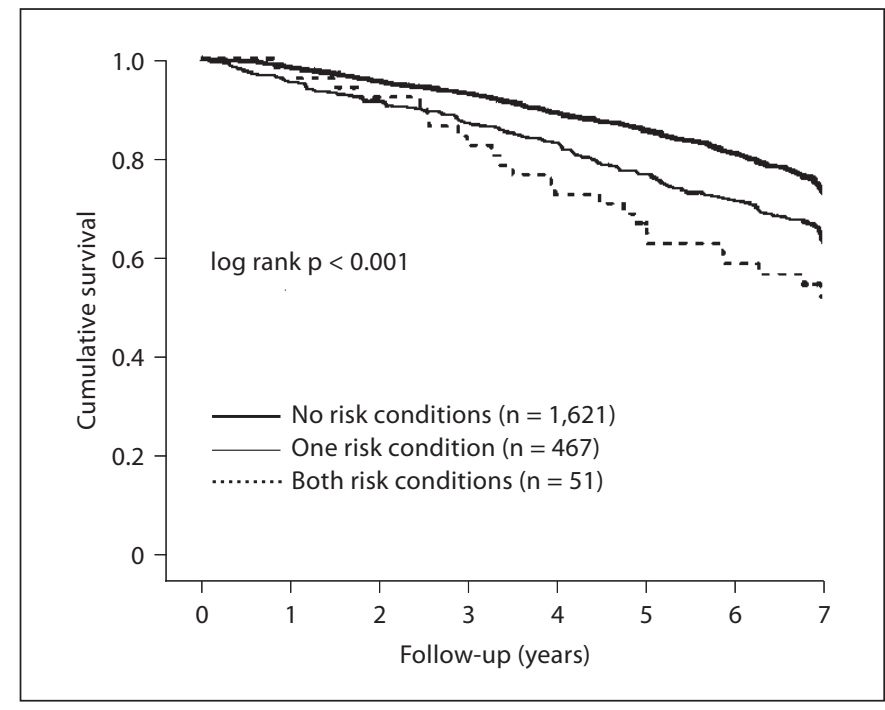

Fig. 2. Kaplan-Meier survival curves for mortality according to the number of high-risk groups (defined as 'poor' SAHS and slowest walking speed category, i.e., $<0.29 \mathrm{~m} / \mathrm{s}$ ).

SAHS groups showed statistical significant differences (all $\mathrm{p}$ values $<0.05$ ). Significant results were also reported for all the pairwise comparisons performed across the walking speed categories (all p values $\leq 0.05$ ), except for the comparison between the two fastest groups ( $\mathrm{p}=$ 0.07).

Results from adjusted Cox proportional hazard models estimating the mortality risk according to SAHS and walking speed categories are shown in table 2. Statistically significant trends in the association of both variables of interest with mortality were reported. Participants reporting a 'poor' health status at the baseline were more likely to die compared to subjects reporting an 'excellent' health status, even after adjustment for potential confounders (Model 3 adjustment HR 1.55, 95\% CI 1.122.14). Similar results were observed for participants with low walking speed $(<0.29 \mathrm{~m} / \mathrm{s}$; HR $1.71,95 \%$ CI 1.29 2.26) compared to participants with walking speed $\geq 0.81$ $\mathrm{m} / \mathrm{s}$ (reference group).

A statistically significant, but weak, correlation between SAHS and walking speed categories (Pearson's $r=$ $0.069 ; \mathrm{p}=0.001$ ) was reported. Adjusted Cox proportional hazard models (table 2, Model 4) were then performed including simultaneously SAHS and walking speed variables as predictors of mortality. Results showed that both variables of interest were able to significantly and independently predict the study outcome (both $\mathrm{p}$ values for trend $<0.05$ ).
No significant differences in AUCs from ROC analyses were also reported for the prediction of mortality when SAHS (0.557, 95\% CI 0.531-0.583) and walking speed groups $(0.577,95 \%$ CI $0.551-0.602)$ were tested. The combination of the two 4-level categorical variables into a single 8-level categorical variable led to a slight increase in the AUC $(0.595,95 \%$ CI $0.570-0.620)$. On the other hand, both tests showed high specificity for the prediction of mortality. In fact, the specificity of 'excellent' SAHS (compared to all the other combined levels of SAHS) was 0.857 . Similarly, walking speed $\geq 0.81 \mathrm{~m} / \mathrm{s}$ (compared to lower walking speeds) had a specificity of 0.800 in predicting mortality. Very low sensitivity was found for both tests at these cut-points (i.e., SAHS 0.099, walking speed 0.120 ). When the two tests were considered together (i.e., participants with 'excellent' SAHS and walking speed $\geq 0.81 \mathrm{~m} / \mathrm{s}$ vs. all the others) the specificity increased to 0.976 (sensitivity 0.011 ), but the number of subjects with both positive values was extremely low ( $\mathrm{n}=38,2.0 \%$ of the study sample).

Finally, to further evaluate the potential additive value of the SAHS and the walking speed for the estimate of mortality risk, Kaplan-Meier survival curves were performed according to the number of high-risk conditions of death (defined as 'poor' SAHS and the slowest walking speed group; fig. 2). Participants with no risk condition had a longer survival compared to the other groups. Significant differences were maintained even after adjustment for potential confounders (Model 3 adjustment: no high-risk conditions [events/participants $=490 / 1,621$ ] 1 - reference group; one high-risk condition [events/participants $=197 / 467]$ HR 1.34, 95\% CI 1.12-1.59; two highrisk conditions [events/participants $=29 / 51$ ] HR 1.80, 95\% CI 1.22-2.66). No significant interaction term for mortality between walking speed and SAHS was found ( $\mathrm{p}$ for interaction term $=0.28$ ).

\section{Discussion}

In the present study, we evaluated the predictive value for mortality of a self-reported measure of health status and a walking speed test. Our results show that both measures are similarly predictive of mortality among older Mexican-Americans. As shown by the small increment in the AUCs drawn by the combined use of the two measures, a limited additive value is present between the SAHS and the physical performance test for predicting mortality. However, poor results at both tests identify a smaller group of subjects characterized by a particularly 
increased risk of mortality, which was confirmed even after adjustment for several potential confounders.

Our results, consistent with previous reports $[3,5,9$, 25], demonstrate a significant association between physical performance and mortality. Walking speed is more usually associated with the physical disability outcome given the close relationship existing between the walking task and the mobility limitation, a pre-disability state [26, 27]. The innate prognostic value of walking speed for an event apparently not related to lower extremity function (i.e., mortality) can be better understood if this physical performance measure is considered as the extent of cumulative age-related body modifications and/or diseases burden. Interestingly and in line with this hypothesis, extremely small differences in the strength of the relationship between walking speed and mortality were reported between our results from unadjusted and adjusted models. This consistency may suggest that the prognostic value of walking speed is independent of clinical conditions and disease risk factors.

Self-ratings of health are reliable predictors of survival, even when health risk factors are taken into account [11-14]. SAHS may simply provide a more complete and wider evaluation of the health status compared to what can be retrieved by a physician or the evaluation instruments. In fact, as explained by Stenback [28], the patient is the only one having access to sensations arising from within the body. Interestingly, studies with a particularly long follow-up tend to show a decrease of the SAHS predictive value over time $[13,16]$. This phenomenon is in accord with the so-called 'sponge' hypothesis [16] proposing that SAHS predicts mortality mainly because more inclusive than the adopted covariates. On the long term and at very old age, the relationship between SAHS and mortality tends to weaken likely because overwhelmed by the rapid and multiple onsets of new (sub)clinical conditions influencing health status and survival. Overall, our findings based on a $\sim 6$ year follow-up are consistent with previous reports $[12,13]$.

It has also been suggested that the SAHS reflects not only the respondent's own current health, but also the knowledge of family risk factors [11, 29]. The relationship between self-rated health and negative outcomes may also find an additional possible explanation in the dynamic evaluation implied in the assessment [11]. In other words, even a one-point assessment is rated based on (own and others') previous and current health experiences, consequently designing a trajectory of well-being. It is also important to mention how the SAHS can modify behavioral patterns, and influence the adherence to inter-

Self-Assessed Health Status, Walking Speed and Mortality ventions and treatments $[11,30]$, consequently protecting or exposing to events.

Besides of confirming the predictive value for mortality of both SAHS and objective physical performance measures $[9,20]$, the present study presents some novel findings. First, our study was conducted on a community-based population of Hispanic older adults in the USA. The importance of evaluating the relationship between SAHS and mortality in different social and cultural settings (potentially responsible for significant differences) has been previously remarked in literature [13]. To our knowledge, a direct comparison among these instruments for mortality in elders was not yet available in literature. Moreover, the possible interaction between selfreported and objective measures in the elderly has only been sparsely evaluated in cross-sectional studies [31, 32]. Since these instruments (should) play key roles in the overall assessment of older persons, and potentially indicate the potential candidates for specifically tailored clinical interventions, it is particularly important to evaluate their relationships. In this context, the two measures may share similar areas of the older person's assessment. In fact, walking speed might not be merely considered as a measure of physical functioning, but (in a broader extent) as a marker of well-being [9]. Nevertheless, despite the potential similarities, our results show that the walking speed and the SAHS are not strongly related to each other, and they are independent predictors of mortality. Therefore, these findings may support the idea that, even if theoretically they may share a common basis, these measures are indeed capturing different health-related information in the prediction of mortality. This hypothesis may be supported by the different aims and designs on which the two measures were built. Finally, it is noteworthy that similar estimates of risk were reported for walking speed and SAHS in the prediction of mortality. This finding may support the validity of walking speed as a general well-being index [9]. Moreover, the multiple dimension characterization of SAHS and walking speed may explain the limited additional prognostic value showed when combined. It is possible that these variables are so comprehensive that the evaluation of additional factors is superfluous for the improvement of the assessment.

Although statistically significant, our results from AUC analyses were not particularly striking for both SAHS and walking speed in the prediction of mortality ( 0.557 and 0.577 , respectively). These findings may apparently limit the clinical relevance of these measures. Nevertheless, the high specificity shown by both tests 
$(\geq 80 \%)$ provides them with an important role in the screening process. Older patients usually have many more difficulties in following a diagnostic and therapeutic schedule than younger subjects because of the higher burdens imposed by social, clinical, and physical problems. In this context, specificity becomes particularly important because crucial in excluding as many 'false positives' as possible from further potentially irrelevant evaluations and examinations. By showing that both SAHS and walking speed are not only predictive of health-related events (i.e., mortality), but also provided with high specificity, our findings indeed support their use in the clinical setting for the initial evaluation of older persons.

The present analyses were conducted only in H-EPESE participants with valid data for all the variables of interest. The exclusion of subjects with missing data and/or lost to follow-up may have influenced our results, likely underestimating the predictive value of SAHS and walking speed for mortality. In fact, excluded participants were characterized (as often occurring in epidemiological studies) by older age, higher comorbidity, and greater physical disability. These factors, besides of all being predictors of mortality, are also associated with poor quality of life and low physical performance.

Our analyses were performed in a large sample of Mexican-American subjects aged $\geq 65$ years. Therefore, our findings may not be applicable to other age and/or ethnic groups. Moreover, third factors not considered in the present analyses may potentially explain our study findings. Behavioral (e.g., physical activity level) and biological (e.g., hemoglobin levels, nutritional status) factors may have influenced our study results. For example, sedentary, anemic or malnourished subjects may not only experience symptoms (e.g., fatigue) affecting their health status perception and physical performance, but also present an increased risk of health-related events (including mortality) as widely documented in literature.

In conclusion, our study shows that the SAHS and the walking speed test are both significant and independent predictors with a similar strength of mortality in older Mexican-Americans. Subjects with poor SAHS and slow walking speed present higher risk of dying compared to those with only one or none of these risk conditions. However, the additive prognostic value of the two measures is limited.

\section{Acknowledgements}

This research was supported, in part, by the Intramural Research Program of the National Institute on Aging, National Institutes of Health. This study was supported by grants AG10939 and AG17638 from the National Institute on Aging and, in part, by the University of Texas Medical Branch Center for Population Health and Health Disparities (1P50CA105631-02). This work was also supported by the University of Florida - Institute on Aging and the Claude D. Pepper Older Americans Independence Center (NIH grant 1P30AG028740).

\section{References}

1 Applegate WB, Blass JP, Williams TF: Instruments for the functional assessment of older patients. N Engl J Med 1990;322:12071214.

-2 Guralnik JM, Ferrucci L, Pieper CF, Leveille SG, Markides KS, Ostir GV, Studenski S, Berkman LF, Wallace RB: Lower extremity function and subsequent disability: consistency across studies, predictive models, and value of gait speed alone compared with the Short Physical Performance Battery. J Gerontol A Biol Sci Med Sci 2000;55:M221-M231.

- 3 Ostir GV, Kuo YF, Berges IM, Markides KS, Ottenbacher KJ: Measures of lower body function and risk of mortality over 7 years of follow-up. Am J Epidemiol 2007;166:599605.

-4 Guralnik JM, Ferrucci L, Simonsick EM, Salive ME, Wallace RB: Lower-extremity function in persons over the age of 70 years as a predictor of subsequent disability. $\mathrm{N}$ Engl J Med 1995;332:556-561.
5 Guralnik JM, Simonsick EM, Ferrucci L, Glynn RJ, Berkman LF, Blazer DG, Scherr PA, Wallace RB: A short physical performance battery assessing lower extremity function: association with self-reported disability and prediction of mortality and nursing home admission. J Gerontol 1994;49: M85-M94.

-6 Cesari M, Penninx BWJH, Pahor M, Lauretani F, Corsi AM, Williams GR, Guralnik JM, Ferrucci L: Inflammatory markers and physical performance in older persons: the InCHIANTI study. J Gerontol A Biol Sci Med Sci 2004;59:M242-M248.

7 Janssen I, Heymsfield SB, Ross R: Low relative skeletal muscle mass (sarcopenia) in older persons is associated with functional impairment and physical disability. J Am Geriatr Soc 2002;50:889-896 $\checkmark 8$ Rolland Y, Lauwers-Cances V, Cournot M, Nourhashemi F, Reynish W, Riviere D, Vellas B, Grandjean H: Sarcopenia, calf circumference, and physical function of elderly women: a cross-sectional study. J Am Geriatr Soc 2003;5:1120-1124.

9 Cesari M, Kritchevsky SB, Penninx BWJH, Nicklas BJ, Simonsick EM, Newman AB, Tylavsky FA, Brach J, Satterfield S, Bauer DC, Visser M, Rubin SM, Harris TB, Pahor M: Prognostic value of usual gait speed in wellfunctioning elders - results from the Health, Aging and Body Composition (Health ABC) Study. J Am Geriatr Soc 2005;53:1675-1680.

10 Tas U, Verhagen AP, Bierma-Zeinstra SM, Odding E, Koes BW: Prognostic factors of disability in older people: a systematic review. Br J Gen Pract 2007;57:319-323.

11 Idler EL, Benyamini Y: Self-rated health and mortality: a review of twenty-seven community studies. J Health Soc Behav 1997;38:2137. 
12 Mossey JM, Shapiro E: Self-rated health: a predictor of mortality among the elderly. Am J Public Health 1982;72:800-808.

13 Benyamini Y, Blumstein T, Lusky A, Modan $\mathrm{B}$ : Gender differences in the self-rated healthmortality association: is it poor self-rated health that predicts mortality or excellent self-rated health that predicts survival? Gerontologist 2003;43:396-405.

14 Kaplan GA, Camacho T: Perceived health and mortality: a nine-year follow-up of the human population laboratory cohort. Am J Epidemiol 1983;117:292-304.

15 Benyamini Y, Idler EL, Leventhal H, Leventhal EA: Positive affect and function as influence on self-assessments of health: expanding our view beyond illness and disability. J Gerontol B Psychol Sci Soc Sci 2000;55: P107-P116.

16 Lyyra TM, Heikkinen E, Lyyra AL, Jylhä M: Self-rated health and mortality: could clinical and performance-based measured of health and functioning explain the association? Arch Gerontol Geriatr 2006;42:277288.

17 Markides KS, Stroup-Benham CA, Black SA, Satish S, Perkowski LC, Ostir GV: The health of Mexican-American elderly: selected findings from the Hispanic EPESE; in Wykle M, Ford A (eds): Planning Services for Minority Elderly in the 21st Century. New York, Springer, 1999, pp 72-90.
18 Markides KS, Rudkin L, Angel RJ, Espino DV: Health status of Hispanic elderly in the United States; in Marti LJ, Soldo B (eds): Racial and Ethnic Differences in the Health of Older Americans. Washington, National Academy Press, 1997, pp 285-300.

19 Markides KS: Hispanic Established Populations for the Epidemiologic Studies of the Elderly, 1993-1994: Arizona, California, Colorado, New Mexico, and Texas. Galveston, University of Texas Medical Branch, 2003.

20 Simon JG, De Boer JB, Joung IMA, Bosma H, Mackenbach JP: How is your health in general? A qualitative study on self-assessed health. Eur J Publ Health 2005;15:200-208.

21 Radloff LS: The CES-D scale: a self-report depression scale for research in the general population. Appl Psychol Meas 1977;1:385401.

22 Folstein MF, Folstein SE, McHugh P: MiniMental State: a practical method for grading the state of patients for the clinician. J Psychiatr Res 1975;12:189-198.

23 Katz S, Ford AB, Moskowitz RW, Jackson BA, Jaffe MW: Studies of illness in the aged. The index of ADL: a standardized measure of biological and psychosocial function. JAMA 1963;185:94-99.

24 Lawton MP, Brody EM: Assessment of older people: self-maintaining and instrumental activities of daily living. Gerontologist 1969; 9:179-186.

25 Woo J, Ho SC, Yu ALM: Walking speed and stride length predicts 36 months dependen$\mathrm{cy}$, mortality, and institutionalization in Chinese aged 70 and older. J Am Geriatr Soc 1999;47:1257-1260.
26 Chaves PHM, Garrett ES, Fried LP: Predicting the risk of mobility difficulty in older women with screening nomograms - The Women's Health and Aging Study II. Arch Intern Med 2000;160:2525-2533.

27 Ostir GV, Markides KS, Black SA, Goodwin JS: Lower body functioning as a predictor of subsequent disability among older MexicanAmericans. J Gerontol A Biol Sci Med Sci 1998;53:M491-M495.

28 Stenback A: Physical health and physical disease as objective fact and subjective experience. Arch Gen Psychiatry 1964;11:290301.

29 Idler EL, Kasl SV: Health perceptions and survival: do global evaluations of health really predict mortality? J Gerontol 1991;46: S55-S65.

30 Haug MR, Wykle ML, Namazi KH: Self-care among older adults. Soc Sci Med 1989;29: 171-183.

-31 Simonsick EM, Newman AB, Nevitt MC, Kritchevsky SB, Ferrucci L, Guralnik JM, Harris TB; Health ABC Study: Measuring higher level physical function in well-functioning older adults: expanding familiar approaches in the Health $\mathrm{ABC}$ study. J Gerontol A Biol Sci Med Sci 2001;56:M644M649.

32 Fried LP, Young Y, Rubin G, Bandeen-Roche K; WHAS II Collaborative Research Group: Self-reported preclinical disability identifies older women with early declines in performance and early disease. J Clin Epidemiol 2001;54:889-901. 